\title{
O BISCATEIRO FLUTUANTE: A SAGA DE UM INVENTIVO E "ISOLADO" CONSTRUTOR DE ARTEFATOS NA CIDADE DO RIO DE JANEIRO
}

The floating informal worker: the history of an inventive and "isolated" artifacts constructor in the city of Rio de Janeiro

\author{
Luiz Arthur Silva de Faria \\ Paulo Henrique Fidelis Feitosa
}

\begin{abstract}
Resumo
O presente artigo, através da história da construção de uma casa flutuante, erguida pelo "biscateiro" Luiz Fernando Barreto de Queiroz Bispo, entre a favela da Maré (comunidade periférica do Rio de Janeiro) e a Universidade Federal do Rio de Janeiro (UFRJ), desenvolve uma reflexão acerca de saberes populares e científicos, tangenciando a questão da interação entre universidades brasileiras e populações vizinhas, em especial aquelas ditas marginalizadas. Fazendo analogias entre o estudo das redes tecnocientíficas na visão dos Estudos CTS (Ciência, Tecnologia e Sociedade) e o caso brasileiro, onde milhões vivem apartados do que aqui chamamos redes formais, o artigo tenta esboçar caminhos para que esta população, "excluída", se faça presente e inclua variáveis nas equações que regem os processos formais de nossa sociedade. Nesse sentido, o caso em estudo aponta para uma valorização da inventividade - transformadora, indisciplinada - como ferramenta para que "os 'de fora' entrem".
\end{abstract}

Palavras-chave: Casa flutuante; Reciclagem; Inventividade; Inovação; Saberes populares; Redes tecnocientíficas.

\begin{abstract}
In this article, the history of the construction of a floating house, built by Luiz Fernando Barreto de Queiroz Bispo, erected between the Favela da Maré (a peripheral community in Rio de Janeiro) and the Federal University of Rio de Janeiro (UFRJ), was used to develop questions about scientific and popular knowledge, and about the interaction between Brazilian universities and the communities around them, especially those considered as marginalized. This
\end{abstract}


article presents analogies between scientific networks, according to the perspective of science and technology studies, and the Brazilian case, where millions of people live severed from what we call formal networks, and tries to show paths in which this population may participate, and include variables in the equations that govern the formal processes of our society. Therefore, this case study indicates a valuation of inventiveness - transformer, unruly - as a tool for "outsiders to get in."

Keywords: Floating house; Recycling; Inventiveness; Innovation; Popular Knowledge; Scientific networks.

\title{
Flutuando no paradoxo
}

\author{
Todo dia, \\ O sol da manhã vem lhes desafiar \\ Traz do sonho pro mundo \\ Quem já não o queria \\ Palafitas, trapiches, farrapos \\ Filhos da mesma agonia \\ E a cidade, \\ Que tem braços abertos num cartão postal \\ Com os punhos fechados \\ Da vida real \\ Lhes nega oportunidades \\ Mostra a face dura do mal \\ Alagados \\ Trenchtown \\ Favela da maré \\ A esperança não vem do mar \\ Nem das antenas de TV \\ A arte de viver da fé \\ Só não se sabe fé em que ${ }^{1}$
}

Manhã de sol no Rio de Janeiro. Águas calmas e mornas. A brisa vem chegando mansamente, como se pedisse licença. Os reflexos nas águas pintam figuras inusitadas, mistura de cores digna de cartão postal. Por entre verdes árvores se espreitam esguias garças brancas em seu elegante balé matutino. Típico dia carioca. Carros se apressam no asfalto quente, fervente. Buzinam como se o barulho lhes apressasse ainda mais. O odor que a brisa traz bem que poderia ser melhor. Na verdade, é muito ruim, insuportável, mau cheiroso! Restos, madeiras, sacos plásticos, garrafas PET, carrocerias do que já foram carros, lixo cobrindo as margens do mangue poluído e moribundo. E lá, pouco abaixo do viaduto de uma das mais importantes vias expressas da cidade, a Linha Vermelha, no meio da lama fétida do Canal do Cunha, flutua despeitada a casa de Luiz Fernando Barreto de Queiroz Bispo, 
feita de rejeitos reciclados, de frente para a favela da Maré e fundos para o Centro Tecnológico da Universidade Federal do Rio de Janeiro - UFRJ ${ }^{2}$.

A tarefa a que nos propomos neste ensaio é (per)seguir a história deste construtor e do seu artefato nada convencional, tomando como primeira inspiração os Estudos CTS (Ciência, Tecnologia e Sociedade), mormente como apresentados por Bruno LATOUR (2000 e 2001). Desta forma, além d"O Próprio", como Luiz atende ao telefone, colhemos entrevistas com representantes da Universidade (UFRJ), da comunidade da Maré e da esfera governamental (Secretaria Estadual de Ambiente), além da pesquisa por reportagens sobre o tema e da observação direta da casa flutuante. Como referência para este breve estudo, procuramos seguir a linha da Teoria AtorRede (TAR) que, segundo Latour (2005), tem como alguns dos critérios: o papel preciso conferido aos não-humanos; a direção na qual se desenrola a explicação (um "social" estável e servindo para explicar uma situação dada é um indicador de que o estudo não é TAR); verificar se o estudo em questão visa o reagrupamento do social ou se, pelo contrário, insiste ainda na dispersão e na desconstrução.

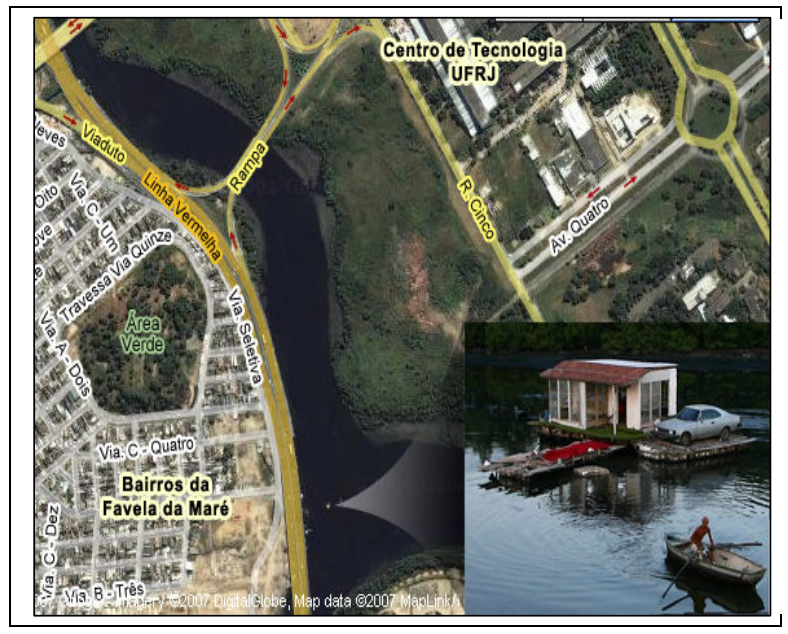

Figura 1 - Representação da situação geográfica da Casa Flutuante da Maré

Alguém poderia de início questionar o interesse de tomar como objeto de estudo um amontoado de lixo, flutuando em meio ao lodo poluído por esgotos, rejeitos industriais e metais pesados ${ }^{3}$, construído por um quase anônimo catador de coisas e inventor de gabarolices. Nossa percepção ao convidarmos o leitor para este desafio é a de que os f/atores ${ }^{4}$ envolvidos na história deste artefato que flutua no centro de um quadro paradoxal - uma vala entre uma universidade brasileira e uma das maiores favelas da cidade (Figura 1) - podem suscitar reflexões: sobre o desenvolvimento de 
conhecimento e tecnologia na "periferia" da ciência, no limite entre o dentro e o fora das instituições formais ${ }^{5}$; e sobre a relação da universidade brasileira com a sua realidade mais imediata, as comunidades de seu entorno. Entretanto, devemos ressaltar que talvez não tenhamos braços para remar por todas essas marés neste nosso não tão vasto artigo.

\section{Alagados, Trenchtown, Favela da Maré: a realidade dos "isolados"}

A música do Paralamas canta a realidade da Favela da Maré em um paralelo com outros dois bairros pobres e periféricos: Favela dos Alagados, em Salvador, capital do estado da Bahia, e Trenchtown ${ }^{6}$, onde foi criado o legendário músico Bob Marley, na capital jamaicana, Kingston. A realidade de isolamento e exclusão fica patente na letra da canção.

Não só na canção como também através de outros relatos é possível resgatarmos um pouco da história, ou histórias, desta comunidade que se confundiu a tal ponto com o mangue, que passou a ser chamada de Maré, denominação comum no nordeste brasileiro para o próprio mangue. A ONG CEASM (Centro de Estudos e Ações Solidárias da Maré), por exemplo, em seu projeto Maré de Histórias, mantém uma coleção dessas histórias ${ }^{7}$.

Elas nos contam que, principalmente a partir do governo de Pereira Passos (1902) e sua reforma urbana, a Maré, que é hoje um conglomerado de cerca de 130.000 habitantes, em diversas comunidades sobre aterros, foi o destino de populações pobres saídas (ou expulsas) de áreas mais nobres disputadas pela especulação imobiliária, de imigrantes nordestinos e até de trabalhadores das obras de aterramento do arquipélago do Fundão para construção da cidade universitária (1949 a 1970), com 5 km², dos quais $3 \mathrm{~km}^{2}$ de aterros. O grande aterramento que hoje abriga a UFRJ teria agravado ainda mais a situação de degradação do ecossistema da região, fechando "vias respiratórias" e importantes berçários de desova de peixes da Baía da Guanabara. Já as palafitas cantadas pela música apareceram no final na década de 40 e se estenderam por toda a Maré até os 80 , quando foram erradicadas através de projetos de aterramentos e construção de moradias pré-fabricadas.

Foi nessa Maré das palafitas, mais precisamente na rua do cais, na Praia de Ramos, que cresceu nosso construtor de artefatos flutuantes. "Eu tomava banho aqui na Maré quando era pequeno", confessa saudoso Luiz BISPO (2007), que construiu sua casa flutuante: um conjugado de alvenaria - com varanda, garagem, carro e piscina - sobre uma balsa de pedaços de isopor, madeira reaproveitada e garrafas PET. Conquanto se autodenomine "um artista", ou ainda melhor, um criador "além da genialidade" (id.,ibid.) e tenha ganhado certa notoriedade, a mídia e as instituições governamentais, 
instâncias formais de nossa sociedade ${ }^{8}$, caracterizam Luiz como um biscateiro, ou seja, isolado das redes formais de emprego. $\mathrm{O}$ "criador" e sua casa-balsa não fazem parte de nenhum projeto apoiado, financiado ou acompanhado por alguma instituição de ensino ou pesquisa. Em primeira instância, seu conhecimento não é "ciência", saber formal. O lixo usado na construção não foi contabilizado, não está nos livros, não faz parte de nenhum empreendimento imobiliário, nem mesmo de projeto de moradia ainda que popular. As amarras que mantém a casa ancorada são frágeis. A qualquer momento uma ordem de desocupação do espaço público ${ }^{9}$, poderia fazer a casa flutuar para fora do mangue. O quadro é de um relativo isolamento.

Com outros sentidos para isolamento e exclusão, LATOUR (2000) conta a história de João da Cruz, um cientista brasileiro dedicado ao desenvolvimento de circuitos integrados no período de reserva de mercado de informática no Brasil. Por causa da abertura para importação de integrados estrangeiros, melhores e mais baratos que os que poderia projetar, ele e seu laboratório ficaram isolados. As redes às quais poderia estar ligado não mais funcionavam no Brasil. Nas palavras de LATOUR (2000), João não conseguiu "se estabelecer como ponto de passagem obrigatória". Não havia mais lugar no mercado, não havia no Brasil pesquisadores com quem compartilhar seus conhecimentos, que para os estrangeiros já eram obsoletos. Cessou o financiamento. João tornou-se um isolado da rede tecnocientífica.

Usando de forma relativizada o conceito de isolamento de Latour e fazendo uma extrapolação à brasileira, podemos arriscar analogamente que, enquanto João da Cruz é o isolado da rede tecnocientífica, Luiz Bispo está relativamente isolado não só de qualquer rede tecnocientífica, como também do que chamaremos mais genericamente de redes formais, aqui consideradas espaços, entidades e processos legalmente estabelecidos nos âmbitos científico, econômico e governamental. Em primeira instância, seu conhecimento não é considerado "ciência", saber formal, e seu "invento" não tem a simpatia da lei ${ }^{10}$ - apesar de diversos exemplos mostrarem que empreendimentos muito parecidos, em locais diferentes e devidamente enredados tiveram sucesso em se estabelecer ${ }^{11}$, como mostra a Figura 2. 


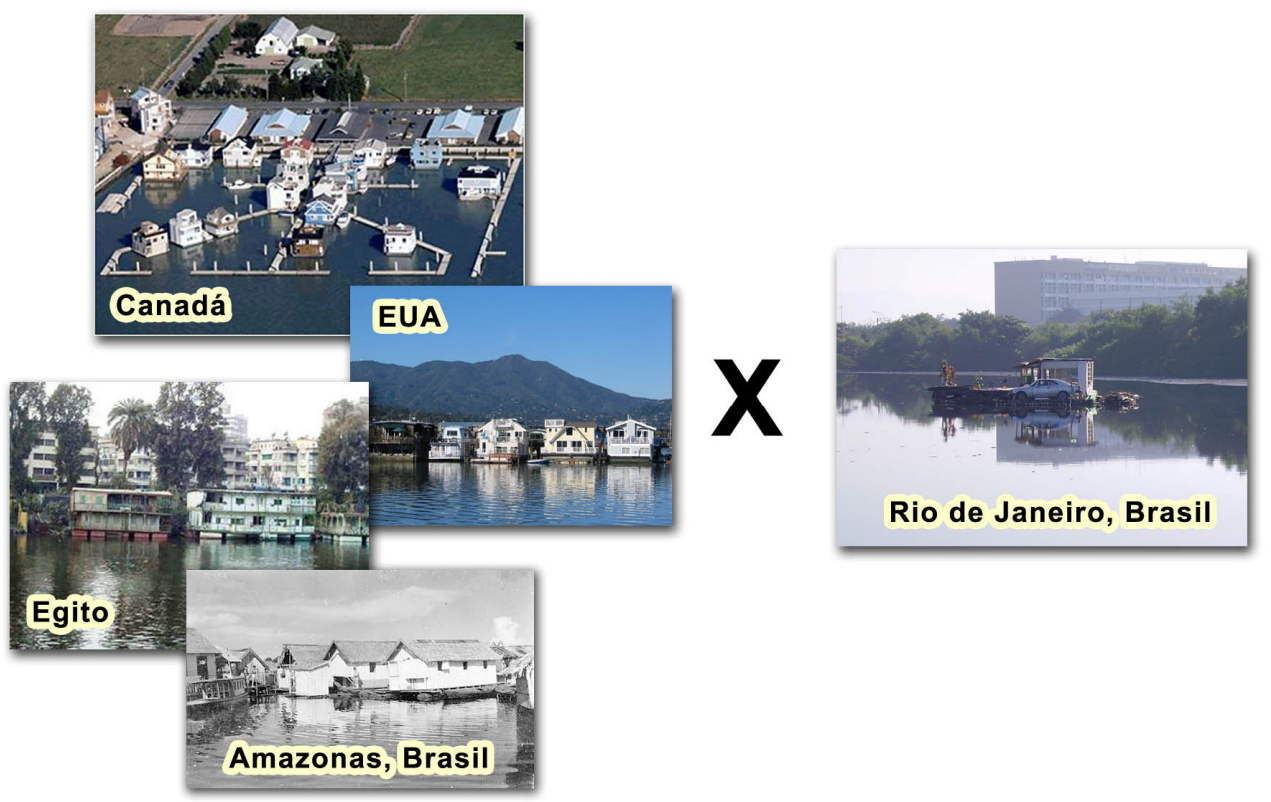

Figura 2 - Casas flutuantes reunidas em condomínios em vários locais do Brasil e do mundo. Na Maré, a casa carioca, aparentemente isolada.

Tanto no caso de Luiz quanto nas redes tecnocientíficas analisadas por Latour, a situação de isolamento é fruto do não enredamento, da ausência de imbricação nas redes que constroem e sustentam fatos e artefatos. Segundo LATOUR (2000):

\footnotetext{
Nunca jamais (sic) se viu fato, teoria ou máquina que sobrevivesse fora da rede que the deu origem. Mais frágeis que cupins, fatos e máquinas conseguem trafegar ao longo de extensas galerias, mas não conseguem sobreviver um minuto nessa famosa e mítica 'exterioridade'.
}

Fatos e máquinas fragilizam-se fora de suas redes, analisa Latour. Luiz e sua casa flutuam aparentemente para longe da formalidade brasileira. Ainda assim, quão isolado estará mesmo o construtor e o seu artefato? Estará irremediavelmente isolado, ou pode-se vislumbrar ainda alguma esperança de aproximação?

\section{A esperança não vem do mar nem das antenas de TV: até onde vai o estranhamento (?)}


Luiz Bispo parece não acreditar que sua esperança de vencer o isolamento possa vir das instituições formais de nossa sociedade, representadas na música dos Paralamas pelas antenas de TV fincadas na colina do Sumaré e avistadas da Maré. Ele reforça o histórico da construção da UFRJ, que segundo ele afetou o ecossistema da região e a geração de renda local, dos pescadores, por exemplo. Apontando para uma garrafa PET, antes flutuante, pergunta: "Estão vendo esse óleo?" (BISPO, 2007). Luiz desconfia que o CENPES $^{12}$ e a Refinaria de Manguinhos têm estreita relação com ele (Figura $3)^{13}$.
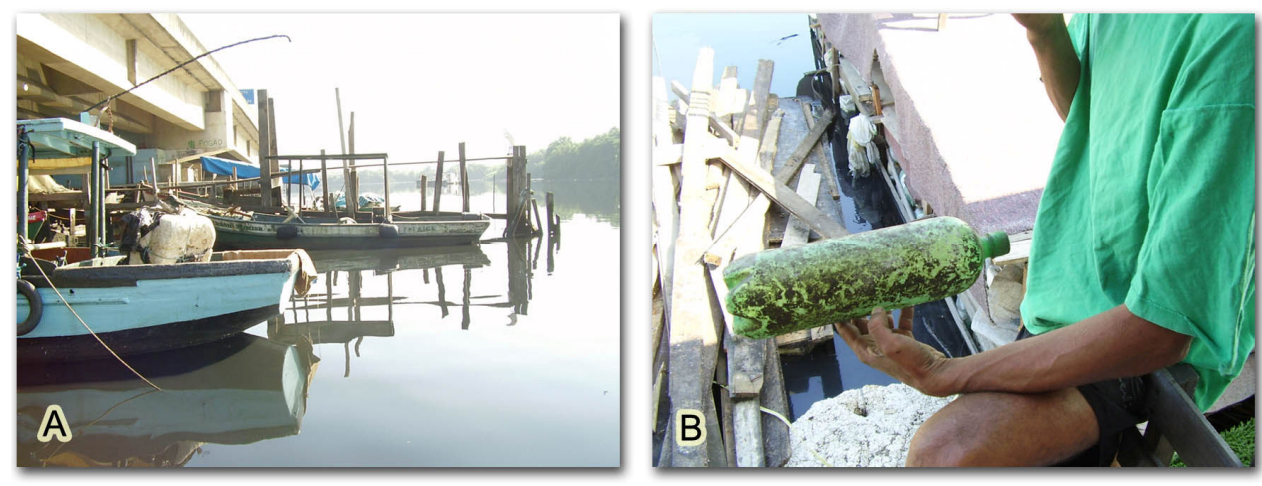

Figura 3 - (A) Barcos da colônia de pescadores abrigados no cais, embaixo da Linha Vermelha. (B) Luiz e uma garrafa PET retirada do mangue: "Estão vendo este óleo?"

"O Próprio" deixa transparecer uma generalizada descrença, a começar "por quem deveria dar o exemplo", citando escândalos nacionais de corrupção envolvendo juízes. Descrença que parece traduzir-se em desrespeito pelas leis (uma ousadia indisciplinada a qual voltaremos na sessão seguinte): Luiz flutuou com a casa até um "lugar de difícil acesso" (id., ibid.), um dia antes de expirar o prazo dado pela SERLA para que retirasse sua habitação flutuante.

A desconfiança é, até certo ponto, recíproca. As instituições parecem indiferentes ou até temerosas quanto aos flutuantes e periféricos eventos/inventos ${ }^{14}$ de Luiz. Para elas, o artefato da Maré infringe a legislação e não se traduz em "uma alternativa de moradia" (SERLA, 2007) - significado diverso, aliás, daquele assumido por artefatos semelhantes em outras redes. Estes emergem menos isolados quando alteramos os espaços e/ou os tempos analisados, como já figurados nos exemplos do Egito, Estados Unidos, Canadá e mesmo em alguns estados do Brasil (Figura 2).

Apesar de certa dose de estranhamento mútuo, indicadores de reconhecimento também surgem de ambos os lados, amenizando o quadro de isolamento e exclusão até agora descrito. Para o governo, Luiz é também, 
sim, um inventor criativo, que passa uma mensagem importante: "não jogue lixo no rio, transforme o lixo em algo criativo" (SERLA, 2007). Reflexões também partem da universidade: Ângela Uller, então diretora da COPPE $U F R{ }^{15}$, entrevistada sobre a questão, vislumbra um "espírito empreendedor e de inovação, que faltam um pouco no Brasil". Também questionada sobre o assunto, a pesquisadora Heloísa Borges do Núcleo de Solidariedade Técnica (SOLTEC/UFRJ) diz que o simples fato de pesquisadores "estarem preocupados em estudar este caso já é um indício de que a Universidade está interessada no artefato e em seu construtor" (BORGES, 2007).

Na mesma direção, mas no sentido contrário, Luiz por sua vez parece tentar flutuar em direção às redes formais: "o mesmo livro que você tem na escola, eu tenho na Biblioteca Nacional", deixando escapar alguma admiração e respeito pelo conhecimento científico: "eu uso o que vocês produzem [na Universidade]" (BISPO, 2007).

\section{A arte de viver da fé: a rede flutuante e a reinvenção da esperança}

Em meio a um misto de isolamento, muita desconfiança e, contraditoriamente, algum crédito nas instituições, Luiz tenta fortalecer seu e/invento por meio da expansão de sua rede. Arriscamos aqui, novamente, a analogia com as redes tecnocientíficas:

\footnotetext{
Toda vez que alguém falar numa aplicação bem-sucedida de uma ciência, procure ver se houve uma extensão progressiva de alguma rede. Toda vez que alguém falar de um malogro da ciência, procure descobrir que parte de que rede foi furtada. Aposto que sempre vai achar. LATOUR (2000).
}

Luiz, como um cientista em ação dos estudos de Latour, amplia sua rede tentando alistar aliados humanos e não-humanos ao seu empreendimento. A rede de Luiz é precária, mas ele se esforça, investe para mantê-la ao menos momentaneamente coesa. Parece apostar na reinvenção, na tradução: "o que é lixo para você, pode ser outra coisa para mim" (BISPO, 2007). Os atores mudam, o lixo passa a desempenhar um papel diferente nesta nova rede, lembrando-nos das observações de John LAW (1997) sobre a mudança de papel das máquinas quando transladadas de uma rede para outra: toda tradução implica em traição (LAW, 1997). No caso brasileiro, o artefato de Luiz progressivamente se transforma. O biscateiro mobiliza de forma criativa os rejeitos da sociedade, que são recombinados: primeiro conformam uma balsa que seria meio de transporte de mudas para replantio na região. Depois, entram em cena garrafas PET, isopor e madeira, que 
passam a compor a lista heterogênea de aliados integrantes da rede flutuante.

É difícil precisar quando esta rede começou a ser tecida, mas certamente foi antes mesmo da própria construção da casa. Luiz afirma ter conhecido moradias flutuantes sobre toras em visitas à Amazônia (Figura 2), onde, segundo Darcy RIBEIRO (1995), "[ao longo do processo civilizatório brasileiro,] foi surgindo uma população nova, herdeira da cultura tribal no que ela tinha de fórmula adaptativa à floresta tropical"16 " "O Próprio" parece ter trazido desta experiência não apenas a idéia da casa, mas, curiosamente, uma postura que traz similaridades com grupos indígenas: pouco amarrados às nossas redes formais, assim como Luiz, segundo VIVEIROS DE CASTRO (2006) os índios vêem os homens brancos "como idiotas hábeis" e "estão mais interessados em nossa capacidade tecnológica do que em reproduzir nossas formas sociais, que em geral desprezam enormemente".

É da Amazônia, segundo seu relato, que vem com o propósito de aprimoramento da balsa, valendo-se também de saberes populares em construção civil: Luiz e seu pai vivem do aluguel de alguns imóveis por eles construídos, dentre eles um "apart-hotelzinho" (BISPO, 2007), ironiza. A balsa é aumentada, ganha alicerce de concreto armado e uma casa (Figura 4) construção simples do ponto de vista das casas de alvenaria. Uma quitinete de tijolos e cimento, bem ao estilo das construções populares cariocas, segundo ele, "respeitando todos os princípios da Engenharia", embora não exista sistema para água e esgoto, lixo e outras necessidades talvez não muito relevantes para uma casa-propaganda que tem até banheira. Estrategicamente seduzindo aliados (uma das formas citadas por Callon (1986) para expandir uma rede, num processo de alistamento), usando a "malandragem de um diretor de novelas" (BISPO, 2007), Luiz convoca os atores e apresenta-os em capítulos (Figura 4D) a fim de ganhar o público aos poucos: primeiro a casa, em seguida a garagem, ocupada por um Opala que, segundo ele "não funciona não, é só pra marketing mesmo" (id., ibid.) e depois a piscina. 

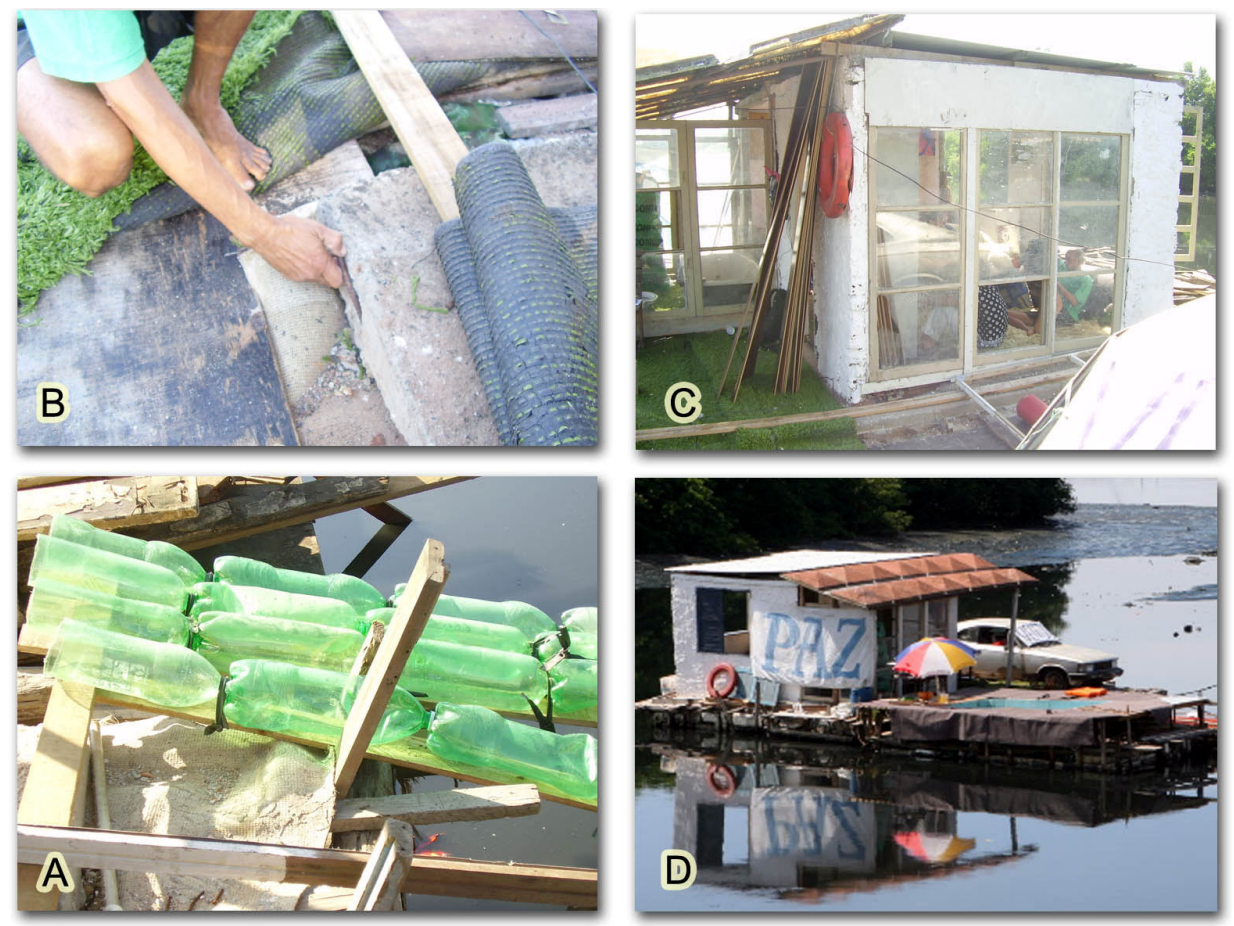

Figura 4 - (A) Detalhe da amarração das garrafas; (B) $O$ alicerce de concreto armado; (C) Vista parcial da alvenaria; (D) Os capítulos da novela: casa, piscina e garagem.

Os rejeitos, reaproveitados da própria Maré, transformam-se em um pequeno "imóvel-móvel" (BISPO, 2007), como o próprio Luiz define a casa. Mesmo a Linha Vermelha, que tenta passar incólume e indiferente pela Maré, torna-se aliada de Luiz e sua casa, na busca por visibilidade: 120 mil veículos diariamente ${ }^{17}$ avistam a casa. Durante a entrevista, um deles reduz a velocidade e uma voz arrisca: "Vou comprar!". "R\$10 mil", retruca Luiz. A balsa, quase um novo ponto turístico da cidade, transforma-se em casa com decoração também reaproveitada, e reinventada (Figura 5). Está pronto o criativo artefato e, de certa forma, está sendo também tecida a sua rede flutuante: segundo Luiz, e não ousaremos discordar, "uma obra de arte" (id., ibid.).

Luiz deposita fé em suas artes, em sua criatividade, possivelmente oriunda do "desejo de transformação renovadora" que "constitui, talvez, a característica mais remarcável dos povos novos, e, entre eles, os brasileiros" (RIBEIRO, 1995). Darcy Ribeiro acrescenta

a criatividade do aventureiro, a adaptabilidade de quem não é rígido, mas flexível, a vitalidade de quem enfrenta, ousado, azares e fortunas, a originalidade dos indisciplinados (id., ibid.). 
E é assim que Luiz constrói sua arte (Figura 5): de forma original, criativa e indisciplinada, ele ousa, a partir da informalidade, aproveitar vestígios de uma sociedade da qual ele está relativamente isolado, para atingir seus objetivos.

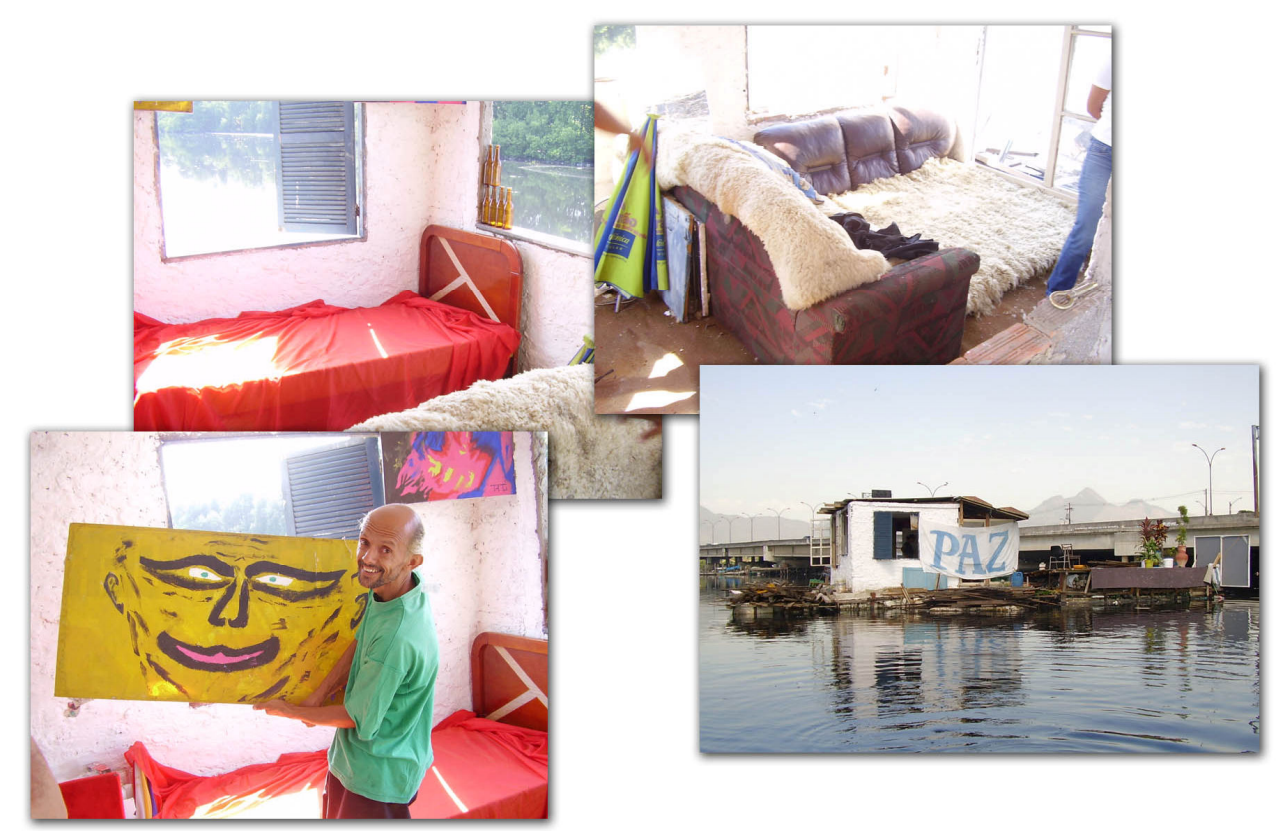

Figura 5 - Da esquerda para a direita, a "obra de arte" de Luiz: sua pintura, "O Sorriso de Maquiavel"; o quarto mobiliado e o projeto de vitral na janela, com garrafas de cerveja; a sala com aconchegante tapete de pele; e a PAZ reciclada.

Chegamos a um ponto de interessante reflexão, onde o "isolado" Luiz, pintado no início de nosso artigo, com o auxílio de Latour, transforma-se em um outro: em certa medida, sua original criatividade traduz-se em algumas conexões, em um relativo não isolamento - articulando como que "fiapos" de enredamento entre sua rede flutuante e redes formais, alguns ressaltados na seção anterior como "indicadores de reconhecimento". Estaria ele, utilizando-se da sua inventividade, conseguindo adentrar no respeitável campo das redes formais? Teria o artefato flutuante servido para minar um certo distanciamento entre vizinhos - a Universidade (e o Estado) e a Maré (e as periferias)? E ainda, poderiam as redes formais combinar saberes "populares e informais" com saberes "científicos e formais"?

\section{Só não se sabe fé em que: a procura de caminhos onde depositar a fé}


A reinvenção parece ser uma chave para a esperança. A história de Luiz Bispo e sua casa mostra uma tentativa de enredamento, utilizando a inventividade como ferramenta. Diferente do movimento "insiders out", apresentado por LATOUR (2000), quando os cientistas saem de seus laboratórios tentando conquistar os não cientistas, legitimando a própria atividade e expandindo as redes tecnocientíficas, o "Biscateiro" parece esboçar um "outsiders in": uma periferia aparentemente desarticulada das redes formais - neste caso não apenas redes tecnocientíficas - buscando reconhecimento, foco, holofotes e enredamento com os "de dentro" - a sociedade, seus processos e instituições formais.

É interessante notar que alguns autores apontam questões de extrema relevância para a tarefa de articular, enredar realidades hoje periféricas. Por exemplo, a valorização de uma visão local, baseada no caso a caso bastante presente nas abordagens sociotécnicas de LATOUR (2000 e 2001), CALLON (1986) e LAW (1997) -, é fundamental para a provocação de MARQUES (2005) que, situando a discussão no contexto brasileiro, traz para o centro a indagação de quais "f/atores brasileiros 'transbordam' dos quadros de referência adotados". Ou seja, quando lidando com situações concretas, temporal e localmente definidas, que f/atores são levados em conta para a definição ou circunscrição dos quadros de referência que servirão de base para as tomadas de decisão. Marques ressalta que a concepção/adoção de um quadro de referência subentende a inclusão de certos f/atores e, por certo, a exclusão de outros.

No caso brevemente estudado, Luiz, ainda que não intencionalmente, mostra um caminho intrigante para fazer face ao desafio traduzido acima por Marques. De forma inusitada e despeitada, utiliza-se de uma inventividade transformadora e indisciplinada, para fazer-se presente e enfatizar variáveis antes quase ausentes nos quadros de referência locais ${ }^{18}$.

No desafio brasileiro de buscar modelos inclusivos de desenvolvimento e, em especial, de encontrar ferramentas de que possam dispor aqueles alijados dos processos formais, a inventividade, ilustrada aqui pelo caso de Luiz, destaca-se como ferramenta - ainda que incipiente - para enredaremse, articularem-se, fazerem-se presentes e incluírem variáveis antes fora das equações que regem os processos formais de nossa sociedade.

\section{Notas}

1. Letra da música Alagados de Herbert Vianna, Bi Ribeiro e João Barone.

2. Tanto a construção quanto seu construtor receberam destaque na mídia escrita e de TV nos anos de 2007 e 2008. O fato da casa ter sido totalmente construída com material reaproveitado, somado ao local onde está ancorada e à figura exótica de Luiz, certamente contribuíram para aguçar a curiosidade coletiva. Atualmente (março de 2009) uma segunda versão da casa encontra-se ancorada no mesmo local, agora com dois andares. 
3. Conforme a Secretaria de Ambiente do Estado do Rio de Janeiro. Disponível em $<$ http://www.ambiente.rj.gov.br/> acessado em 15.05.2007.

4. Expressão utilizada por Marques (2005), indicando simultaneamente a presença de fatores e atores em determinado processo.

5. Um dos assuntos principais dos Estudos CTS é a formação das redes que fazem e sustentam fatos e artefatos tecnológicos.

6. Recebeu este nome devido à grande vala que percorre o bairro, conforme informações disponíveis em <http://en.wikipedia.org/wiki/Trenchtown> acessado em 15.05.2007.

7. CEASM. Disponível em <http://www.ceasm.org.br> acessado em 15.05.2007.

8. Secretaria Estadual de Ambiente (RJ) e SERLA - Fundação Superintendência Estadual de Rios e Lagoas.

9. Ameaça explicitada pela então presidente da SERLA, Marilene Ramos, como informou a reportagem disponível em <http://oglobo.globo.com/rio/mat/2007/03/01/294756232.asp> acessada em 03.05.2007.

10. Conforme ameaça de desocupação explicitada pela então presidente da SERLA, Marilene Ramos, como informou a reportagem disponível em <http://oglobo.globo.com /rio/mat/2007/03/01/294756232.asp> acessada em 03.05.2007.

11. Exemplos destes podem ser verificados no Canadá <http://www.floathomepacific.com/>, Gravataí-RS <http://aprendiz.uol.com.br/content.view.action?uuid=5b94a2bd0af4701 00140984bfc2488a8>, Cairo <http://www.bbc.co.uk/portuguese/reporterbbc/story/2005 /07/050713_arabicasrs.shtml>, acessados em 20.05.2007.

12. CENPES - Centro de Pesquisas da Petrobrás.

13. Ainda, diz que pretende registrar seus inventos no INPI (Instituto Nacional da Propriedade Industrial), mas acha que pode haver um esquema de roubo de idéias.

14. Fazemos aqui um paralelo com a expressão "f/atores" utilizada por MARQUES (2005). No caso apresentado, além do aspecto do "invento", nos parece pertinente a análise da construção do artefato como um "evento", no sentido da definição de LATOUR (2001), que define um experimento como um "evento", em lugar de "descoberta", trazendo conseqüências para a historicidade de todos os seus ingredientes, humanos e não-humanos. Daqui em diante usaremos a expressão simplificada "e/inventos".

15. COPPE - Instituto Alberto Luiz Coimbra de Pós-Graduação e Pesquisa de Engenharia.

16. Capítulo "O Brasil Caboclo" em RIBEIRO (1995). Segundo Darcy, nos primeiros anos da invasão européia metade dos cerca de 5 milhões de índios "brasileiros" viviam na Amazônia, e "[a] grande novidade com respeito aos povos que sobreviveram aos séculos de extermínio, até agora, é que vão sobreviver no futuro. Ao contrário do que temíamos todos, estabilizaram-se suas populações e alguns povos indígenas estão crescendo em número [...] [, a]pesar de que jamais alcançarão o montante que tinham nos primeiros tempos da invasão européia."

17. Segundo o "Plano de Ação para Redução de Poluentes Atmosféricos em Aeroportos" disponível em <http://ivig.coppe.ufrj.br/doc/infraero1.pdf> acessado em 03.05.2007.

18. Exemplo: Luiz foi convidado para compor a mesa em debate sobre reciclagem organizado pela Decania do CT - Centro Tecnológico da UFRJ. 


\section{Referências}

ACKERMANN, Luciana, 2007. Minc quer levar casa flutuante para Museu do Meio Ambiente. O Globo Online, Rio de Janeiro, 02 mar. 2007. Disponível em <http://oglobo.globo.com/rio/mat/2007/03/02/294775253.asp>. Acesso em: 10 mai. 2007.

BISPO, Luiz Fernando de Q.. 2007. Sua história e a da casa flutuante. Rio de Janeiro: 12.05.2007. Entrevista concedida a Luiz A.S. de Faria, Paulo H.F. Feitosa e Flávio C. Henriques.

BORGES, Heloísa, 2007. Sobre a casa flutuante no canal do Cunha. Rio de Janeiro: 08.05.2007. Entrevista concedida a Luiz A.S. de Faria, Paulo H.F. Feitosa.

CALLON, Michel, 1986. Some Elements of a Sociology of Translation: Domestication of the Scallops and the Fishermen of St Brieuc Bay In: LAW, John. Power, Action \& Belief. A New Sociology of Knowledge? London: Routledge. p.196-229.

ENTREVISTA A LUIZ FERNANDO BISPO. Programa do Jô. São Paulo, Globo, 09.04.2007. Programa de TV.

LATOUR, Bruno. Ciência em ação: como seguir cientistas e engenheiros sociedade afora. Tradução: Ivone C. Benetti. Revisão: Jesus de Paula Assis. São Paulo: Editora UNESP, 2000 [1998].

A esperança de Pandora: ensaios sobre a realidade dos estudos científicos. Tradução: Gilson César C. Souza. Bauru, SP: EDUSC, 2001 [1999].

Reassembling the Social - An Introduction to Actor-Network-Theory. New York: Oxford University Press, 2005.

LAW, John. Traduction/trahison: notes on ANT. Lancaster: Centre for Science Studies, Lancaster University. Disponível em: <http://www.comp.lancs.ac.uk/sociology/papers/Law-Traduction-

Trahison.pdf>. Acesso em 04 mai. 2007. 
MARQUES, Ivan da Costa. Engenharias brasileiras e a recepção de fatos e artefatos In: LIANZA, Sidney, ADDOR, Felipe (Org.). Tecnologia e desenvolvimento social e solidário. Porto Alegre: Editora da UFRGS, 2005. p. 13-26.

Sobre a proposição dos Labordireitórios. Curitiba: 06 nov. 2007. Mesa redonda "Ciência, tecnologia e sociedade", do II Simpósio Nacional de Tecnologia e Sociedade.

RIBEIRO, Darcy. 0 povo brasileiro: a formação e o sentido do Brasil. São Paulo: Companhia das Letras, 1995.

RIO DE JANEIRO (Estado). Secretaria Estadual do Ambiente, 2007. Secretário do Ambiente visita dono de casa flutuante no Canal do Cunha. Rio de Janeiro. Disponível em: $<$ http://www.ambiente.rj.gov.br/detalhe_noticia.asp?ident=47>. Acesso em 02 mai. 2007.

SERLA ??. Casa flutuante vira ponto de visitações. Rio de Janeiro, 09 mar. 2007. Disponível em: <http://www.serla.r.gov.br/noticias /noticia_dinamica1.asp?id_noticia=285>. Acesso em 02 mai. 2007.

Serla vai retirar casa flutuante do canal do cunha. Rio de Janeiro, 01 mar. 2007. Disponível em: <http://www.serla.rj.gov.br /noticias/noticia_dinamica1.asp?id_noticia=280>. Acesso em 10 mai. 2007.

ULLER, Ângela. Sobre a casa flutuante no canal do Cunha. Rio de Janeiro, 08 mai. 2007. Entrevista concedida a Luiz A.S. de Faria, Paulo H.F. Feitosa.

VIVEIROS DE CASTRO, Eduardo B., 2006. Índios vivem dilemas semelhantes aos que o Brasil enfrenta. FAPERJ, 29 jun. 2006. Entrevista concedida a Vilma Homero. Disponível em: <http://www.faperj.br/boletim_interna.phtml?obj_id=2949>. Acesso em 24 mai. 2007. 